\title{
Peace Teams in the Protest-Repression Nexus: A Sociomaterial Perspective of De-escalatory Tactics
}

\author{
Richard N. Canevez \\ University of Hawaii at Manoa \\ $\underline{\text { rcanevez@hawaii.edu }}$
}

\author{
Jenifer Sunrise Winter \\ University of Hawaii at Manoa \\ jwinter@hawaii.edu
}

\begin{abstract}
Peace teams work in the trenches of demonstration in liberal democracies. When situations between different parties can escalate to violence, they deploy various tactics and tools to de-escalate the situation. Their work navigates a web of institutions and actors, as well as tools that introduce their materiality into de-escalatory practices. Depicting this system stands to highlight how Peace Teams an maximize their capacities both socially and technologically. However, to date there is no cohesive social and material account of Peace Team work. This study adopts a sociomaterial perspective of demonstrations through the eyes of Peace Teams and their de-escalatory tactics, using semi-structured interview and focus groups. We provide theoretical insights about the sociomaterial nature of de-escalation as being a confluence of social and material intra-actions, and argue for bases of trust as an underlying mechanism to account for the configuration of particular sociomaterial assemblages as manifest in the protest-repression nexus.
\end{abstract}

\section{Introduction}

Following the murder of George Floyd in May of 2020, Black Lives Matter demonstrations took place nationwide. Although largely nonviolent, violent challengers like right-wing counter protesters and police reprisals invited violence by demonstrators that was latched onto by the media. This provided a springboard for opponents of the movement to cast the demonstrators as rioters and looters in an attempt to sway public opinion against them [1].

Peace Teams activated during these events as forces of de-escalation that use a variety of de-escalatory tactics "to prevent violence and aggression" [2]. In addition to providing safety for demonstrators, they help movements maintain nonviolent discipline. By helping demonstrators remain nonviolent, Peace Teams help movements build achieve broad support which Stephan and Chenoweth [3] show is critical to a movement's success. Therefore Peace Team work stands to be extremely valuable in continuing social progress in liberal democracies that depend on free speech and freedom of assembly.

Demonstrations today are highly technologized [4] as virtual and physical spaces converge, driven by the wide availability of constant connectivity technologies like cell phones and telecommunications infrastructure [5]. While information systems (IS) scholarship largely focuses on digital technologies within social movements, tools in demonstrations are in fact much broader, including non-digital tools that interact with digital ones and social actors. A full understanding of Peace Teams and de-escalation necessitates a broad view of the embeddedness of their tactics, as acting between demonstrators, authorities, digital and non-digital technologies, and the entanglement of these entities.

To engage the interconnected nature of the protest-repression nexus, we adopt the perspective of sociomaterial assemblages, characterizing it as a system composed of social and technical entities with emergent properties [6]. Peace Teams are embroiled in assemblages that include police, demonstrators and organizers, counter-protesters, and tools and technologies. De-escalatory tactics that Peace Teams use are actions within this system, or "intra-actions" insofar as they emerge from the relationships between social and material actors $[6,7]$.

Research on Peace Teams and de-escalatory tactics marks an extension of IS scholarship in two ways. First, Peace Teams are an understudied but increasingly important aspect of social movements. Second, it continues a trend in IS research recently established by Tarafdar and Kafal Ray [8] towards finer grained sociomaterial analyses of social movements. Therefore, we explore what is the shape of the sociomaterial assemblage that underlies intra-active de-escalation tactics as deployed by Peace Teams? By doing so, we produce theoretical insights from de-escalation as 
intra-action within this sociomaterial assemblage.

\section{Background}

\subsection{Background on Peace Teams}

Although there is vigorous debate as to the efficacy of nonviolent civil resistance in social movements [9, 10], seminal scholarship by Stephan and Chenoweth [3] shows that, almost irrespective of context, nonviolent movements are more effective in achieving long-term success by gaining broad participation and support. Organizations like Peace Teams that help maintain nonviolent discipline and safety are therefore an integral component of social progress.

Peace Teams operate under a few different labels, including violence interrupters [11] or unarmed civilian protection (UCP) teams $[12,13,14]$. Although today they define the bounds and practices of their volunteer work in distinct ways as governed by their own organizational inclinations and local contexts, they trace their lineage to Mahatma Gandhi's notion of a 'Peace Army, or 'Shanti Sena' [12]. In Gandhi's mind, these unarmed armies would interposition themselves in conflict between aggressors and their targets. During escalation, these interruptions can make all the difference between a peaceful resolution and a violent one [15].

Extant scholarship on Peace Teams argues for their efficacy in peacekeeping in comparison to militarized approaches $[16,17,13]$ and the potential to reduce overall violence in urban centers [18]. Evaluation and assessment studies provide further support for Peace Team activity, including empirically supporting their efficacy in reducing violence $[19,20]$ and the benefits of participation, such as job opportunities and improved future outlook for at-risk team members [19].

Scholars with connections to on-the-ground experiences of Peace Teams provide organizational and tactical surveys of their practices, forming the foundations for empirical research on Peace Teams and extending argumentative cases. The tactics of both mitigating state-sponsored violence and violent flanks within a movement are goals that Peace Teams support, integrating their own tactics and practices in support of broader activist movements who are developing their own tactics of violence management [21]. Schweitzer [22] and Julian and Schweitzer [12] covered this ground in identifying Peace Teams worldwide and the various definitions of unarmed civilian peacekeeping that lead to different de-escalatory practices. Julian [16] deepened our understanding by then characterizing Peace Team practices across three dimensions: a) deterrence of violence by presence; b) engagement with armed potential escalators; and c) building relationships between stakeholders. The connective logic in this scholarship is that the particular arena of deployment, be it regional or situational, shapes how these dimensions manifest in practice. This includes teams in the global north like the United States [12].

\subsection{Peace Teams in the Protest-Repression Nexus}

The racial justice demonstrations of 2020 following the police murder of George Floyd tested the nonviolent ideologies and tactics of these Peace Teams. This space was the United States' version of the 'protest-repression nexus' [23]. This nexus constitutes a dynamic, reciprocal interaction between forces, with conventional thought focusing on protesters and state agents (police, military) as the primary elements of confrontation. Here, displays of hostility by opposing sides beget further hostility [24]. Extant scholarship shows how different forms of repression impact dissent choices and can lead to tactical shifts in forms of resistance [25, 26, $3]$ and affect the likelihood to employ more repression in the future [27, 28]. On the other hand, scholarship also shows how forms of resistance can likewise impact repression choices, such as the choice of guerilla warfare tactics [29] and, more broadly, the efficacy of a movement in challenging state authority [23, 3]. The evolution of understanding in this space now includes the potential impact of 'violent flanks' that introduce violent tactical choices into social movements [30], as well as counter-protesters targeting the demonstrators themselves [31].

Extant scholarship is evolving to fit the current awareness of the actors in the protest-repression nexus. However, this also highlights the value of incorporating understanding of Peace Teams into the relational dynamics that characterizes this scholarship. As being potentially valuable to maintaining nonviolent discipline, their work is directly tied to tactical choice.

Beyond the relationship between social movement organizations and Peace Team organizations, broader relational views of Peace Teams focuses on connections to local context, motivated by the observation that peace practices are strongly influenced by local conditions [12]. This backdrops Peace Team work, emphasizing the development of community connections, and in particular the essential role of trust in these connections [11]. It also lends depth to understanding the ideological backing of peace work in influencing perspectives of violence that inform practices $[32,33]$.

Despite the scholarship exploring the connected web 
of social actors to Peace Team organizations, efforts to explore the tools and their material role in Peace Team work has not materialized at the same level. This stands to miss critical insights about Peace Teams and their tactics in the protest-repression nexus given the latter's ostensibly 'hybrid' existence where the virtual and the physical exist in a state of overlap [4]. The closest proximate scholarship is on social movements (with which Peace Teams engage, but are distinct in purpose and tactics) $[8,34,35]$, but are largely restricted to digital spaces. The crux of demonstrations being on-the-ground calls for a broader understanding of tools within this space as having a material presence in the practices of social movements, and in turn, Peace Team organizations.

\subsection{Theoretical Framing}

The actors within the protest-repression nexus exist in a dynamic, entangled state. To engage these factors through the under-explored eyes of Peace Teams attached to (but distinct from) standard social movements in demonstrations, we adopt a sociomaterial perspective. This perspective holds that humans and technology are constantly intertwined in work [36, 37], constituting a collective assemblage of entities to form a whole $[38,7]$. We believe that the protest-repression nexus is a sociomaterial assemblage within which Peace Teams are embroiled, and we therefore view their actions as 'intra-actions,' or actions that emerge from their place within the assemblage $[36,8]$. This is particularly intuitive for de-escalatory tactics, which operate along the lines of relations from Peace Teams to different social actors in the assemblage. Furthermore, the assemblage can be viewed dynamically, as encounters between social and technical actors change over time in a continuous feedback loop [39], allowing us to understand intra-actions in light of previous encounters.

Tarafdar and Kajal Ray [8] theorize social protest cycles as the "micro-foundation" of social movements. The social protest demonstration can be considered a 'micro-micro-foundation' in a similar fashion, continuing the trend towards finer-grained analyses of social movements. We first set out to depict the sociomaterial assemblage and de-escalatory intra-active tactics used by Peace Teams in our research question: What is the shape of the sociomaterial assemblage that underlies intra-active de-escalation tactics as deployed by Peace Teams? By answering this question, we seek to contribute theoretical insights to sociomateriality through a perspective of Peace Teams in the protest-repression nexus.

\section{Methods}

To answer these questions, we conducted semi-structured interviews and focus groups with nonviolence workers and intellectual leaders. We recruited participants through engagement with a network of Peace Teams and peace activists, with assistance from Pace e Bene Nonviolence Service, an independent, non-denominational, non-profit organization that promotes nonviolent approaches to social action. To focus on violence intervention experience at demonstrations, we prioritized organizations that have worked these events, which resulted in participation from DC Peace Team (Washington DC) (4), Portland Peace Team (Portland, OR) (4), and Meta Peace Team (Michigan) (only 1 member responded to the invitation). We also included other participants who could contribute their personal experiences in demonstrations (an additional 8 participants).

We conducted 2 focus group and 6 individual interviews (17 total participants) via Zoom from March to May of 2021. Each individual or focus group interview took between 1 and 2.5 hours. Participant ages ranged from the "25 to 34 year-old" bracket all the way to "above 65 years old". We asked questions pertaining to personal and organizational experiences managing and mitigating violent repression during demonstrations, as well as the use of various technologies and tools in supporting tactics ${ }^{1}$. In semi-structured manner, we also explored emergent topics.

We then used qualitative, reflexive thematic analysis $[40,41]$ stipulating familiarization, code generation, and theme construction. The process of theme construction is "akin to processes of engineering or design" built from meaningful patterns of codes [41], and so we gleaned insights from the constructive process across the interview and focus group transcripts. We conducted our qualitative coding using QDA Miner Lite. We approached the analysis inductively without a priori themes, but were sensitized to the relationships between actors and tools. We also adopted idealist ontological and constructionist epistemological stances, which emphasizes the social embeddedness of experiences [40] and allowed for a deeper reading behind participant experiences.

\footnotetext{
${ }^{1}$ You can view the Interview Protocol here:
https://tinyurl.com/5adhx8ur.
} 


\section{Findings}

Our research question asked What is the shape of the sociomaterial assemblage that underlies intra-active de-escalation tactics as deployed by Peace Teams? Here we explore that topic in terms of team structure, the various network of actors around Peace Teams, and their tools and de-escalatory tactics.

\subsection{Experiences with Violent Repression}

Peace Teams characterize the body of de-escalatory tactics as direct responses to forms of violent repression. When asked to describe their experiences with violent repression, participants spoke of physical violence such as physical attacks by state authorities through munitions, chemical irritants, physical striking, and 'picking,' where police select a seemingly arbitrary person from a group of people and seize them, a process that takes place in full view of other demonstrators. They also reported police also use repressive forms of spatial control, most notably 'kettling,' where police create a confined space where entry and exit is strictly controlled.

Participants also described counter-protesters and demonstrators themselves as sources of violence. Counter-protesters would threaten physical violence, which can be particularly frightening in states with open-carry laws ${ }^{2}$. Counter-protesters also would conduct verbal attacks, such as de-humanizing slurs directed at demonstrators. Thus, participants conceptualized 'violence' as not just harms to the body, but also to psychological harms.

Demonstrators too can participate in violent acts, particularly in response to police or counter-protesters. Peace Teams in these cases intervene to help activists maintain their nonviolent discipline, which bolsters a movement's overall efficacy [3]. While direct intervention work can be dangerous at times, members are trained to preserve their own safety.

\subsection{Deployment Relationships and Structure}

Peace Team members described trying to build relationships with demonstration organizers during the lead-up phases. This involves sitting in on meetings, learning the role they are to play, and establishing norms of expectation, a process participants considered to be building necessary trust. Peace Teams may withdraw from an event if their norms do not match, i.e. where violent methods are accepted or they are to act as informants for police. Here, failure to establish trust

\footnotetext{
2'Open Carry' in the United States is the open display of a live firearm.
}

that organizations share views on means and ends could block Peace Team participation.

A critical distinction between different Peace Teams is whether they will attend a demonstration without an explicit invitation from a social movement organization. For instance, Portland Peace Team was sidelined throughout most of 2020 due to lack of invitation despite the increased racial justice demonstration activity following the murder of George Floyd. This, they reported, was a result of the adoption of violent tactics by the social movement organizations that rose to prominence at the time, which disagreed with the nonviolent ethos of the Peace Team. When trust in a shared set of means cannot be established, Peace Teams can be sidelined.

Although different Peace Teams will display distinct structures during deployment, it is nonetheless helpful to depict a key case that illustrates a typical structure. The DC Peace Team, as an example, deploys a combination of on-the-ground teams integrated directly into the demonstration with coordination provided by remote-support personnel that monitor information sources through social media for situational awareness. On-the-ground teams are composed of smaller units fulfilling interconnected roles: frontline members dispersed throughout groups of demonstrators on ground level; a scouting, supporting member that moves along the periphery of those demonstrators (colloquially called "Care Bears"); and emergency drivers that can quickly ferry away a targeted individual to safety ("extraction"). Frontline members provide direct de-escalation, rotating between Care Bear and frontline roles as needed, and can arrange for the extraction of a person targeted for violent repression to an awaiting emergency driver. On-the-ground team leaders coordinate with members of their on-the-ground team, other team leaders, and remote support team members.

Remote support team members are distanced from the demonstration (e.g. one member lives in Scotland), monitoring the media and information ecosystem before and during an event. This entails constant monitoring of various Twitter accounts that they identified in the lead-up to a demonstration, and using TweetDeck ${ }^{3}$ for real-time consumption and analysis. They track live streams and tweets from journalists and activists, filtering actionable information to on-the-ground team leaders. This information can include the movement of police and counter-protesters near Peace Teams or demonstrators, or other potential sources of escalation. Eli McCarthy, with the DC Peace Team, described the

\footnotetext{
${ }^{3}$ TweetDeck is a Twitter visualization platform for viewing multiple accounts side-by-side.
} 
role this information plays in situational awareness and providing early warnings of violence:

[...] we would get messages from the remote team, like, "there's 100 proud boys at 15 th and $\mathrm{K}$ marching north". And we could then figure out based on where we were, usually around Black Lives Matter Plaza, you know, should we send people in that direction. [...] So we use that information in real time to then develop responses and maybe communicate that with other people on the ground.

Although not all teams currently use remote support (e.g. Portland Peace Team), participants did express interest in adopting these methods in the future.

\subsection{De-escalation Tactics}

Paralleling basic concepts of unarmed civilian peacekeeping identified by Julian and Schweitzer [12], we dimensionalize the reported de-escalation tactics during demonstrations as a) communication tactics; b) physical tactics; and c) spatial management tactics. Although distinct Peace Teams will differ in which tactics they use, these reported tactics largely compose the space of available options available to teams. Here we present them in turn.

As unarmed peacekeepers, the most relied upon tools for de-escalation center on communicative practices, most notably the use of the CLARA method [42]. Sal Corbin, a member of the DC Peace Team, described communication tactics as a re-direction of energy, to "siphon off that energy into something that's non-related." Alejandra Moreno, a member of Portland Peace described a cellphone as a useful centerpiece of de-escalation:

[...] phones are great [as a distraction method] [...] if someone's talking about something very passionately you can distract them by like, searching for something on your phone, or [...] taking a picture of a group [...] like, "oh you're all together and you might wanna take a [photo]?" [...] and by that point, everyone else is gone.

Similar distraction tactics include using unrelated queries like asking for directions or commenting on materials in the immediate vicinity like help with a cellphone or someone's clothes.

Team members also reported using reminders of humanity (re-humanizing) as a verbal de-escalatory tactic by holding themselves out to an escalating person as someone who is willing to listen and appreciate their perspective, even if they may not agree with it ideologically. This is an emotionally challenging tactic, and members reported that it requires putting aside one's own personal ideologies in service to de-escalation. This was also one of the few tactics that participants reported using to de-escalate police in a direct manner by reminding them of their place in a broader community. A leader of the Portland Peace Team, Dr. Tom Hastings recounted pre-emptively de-escalating police during the Occupy Portland demonstrations:

[...] there were cops, some on horseback, cops in complete riot gear, ready to go [...] and I had a conversation at every single one of their units before I [...] went back home and my conversation was basically "Look, you know, you guys, you really in terms of public relations, you have managed to be at least equal with Occupy because you restrained yourselves. I'm very worried that somebody is going to get hurt tonight. And if you hurt somebody tonight, you're going to lose. You will lose and you will be in bad shape in terms of publicity in how Portland looks at you. So I'm asking you, please don't hurt anybody tonight."

He noted that the application of this type of tactic might be a distinctive feature of the Portland locality, being a comparatively tight-knit community compared to many other Peace Teams' regions, such as the DC Peace Team. By comparison, one DC Peace Team member intimated that, while they have a host of tactics that they use for counter-protesters and demonstrators, they feel much less confident de-escalating the police.

Further complicating relationships with police is that direct communication with officers during demonstrations can negatively affect how demonstrators view Peace Teams, and compromise the trust that Teams build with demonstrators. There was broad consensus across participants that being linked to police can have a profound negative impact on trust with social movement organizations and demonstrators. There appears to be a symbolic value of de-escalation, and that none of these tactics take place isolated from other actors in the protest-repression nexus. When Peace Teams engage with certain actors, trust with others in their network can become compromised.

In addition to the communication tactics at Peace Team disposal is an array of direct physical intervention tactics. Commonly used in conjunction with communication, physical intervention focuses on 
bodies, either the use of the team member's body or in extracting targeted persons in order to de-escalate a situation. In the case of the former, Peace Team members reported physically interjecting themselves between belligerents ("interpositioning"), adding an additional layer of humanity they would need to penetrate before physical violence could occur.

A slightly less direct form of physical intervention is accompaniment and extraction, where a team member escorts a consenting and targeted individual away from a potentially escalatory situation. This could be away from police or counter-protesters, ideally ending in a safe location or in a safe vehicle of a team member who will transport them to safety.

The least direct form of de-escalatory tactics used in demonstrations that participants reported is the management of space, using notions of proximity or separation to influence a particular environment. This can involve visual displays of moral authority, separation of spaces occupied by potential sources of escalation, and the setting up of de-escalatory spaces.

The use of moral authority promotes a nonviolent environment based on proximity. Peace Teams could do this directly through the use of clearly marked identification of members, such as a light blue vest, that communicates a peace-making presence. Selecting clear visual identifiers needed to cohere with the local context, as one team member active in Minneapolis reported that the decision to use orange as a vest color proved problematic as it was the same color used by hunters in that region. Teams could also rely on prominent figures of moral authority, and cited their gravity to similar effect. For instance, religious leaders based on previously established community significance, or hereditary chiefs in movements with a matching social and cultural context (i.e. Indigenous-lead movements) could serve in this role.

In some cases, the best way to de-escalate a situation and prevent violent repression is to physically separate demonstrators from potential sources of repression. One participant described the prevention of direct conflict between demonstrators and counter-protesters through the strategic placement of police barricades. Within the teams, remote support personnel provided situational awareness that allowed Peace Teams to inform organizers about potential escalatory parties.

Participants also described the creation of de-escalatory spaces. These could be spaces of healing, like aid stations and healing circles, that communicate a nonviolent presence. One Portland Peace Team member described aid stations within a local church which provided a respite point during potentially intense demonstrations throughout the day. Art installations likewise communicate a nonviolent presence through artistic expression. In these cases, the establishment of spaces with a clear nonviolent orientation works to produce a de-escalated environment.

\subsection{Tools and Technologies of De-escalation}

Although particular tools could differ between organizations (e.g. Portland Peace Team does not make use of remote support teams), we identified the available tools (and surrounding sentiments) as reported by Peace Team participants. As organizations composed of volunteers with varying tech capacities, ease of use and accessibility were essential considerations in tool selection. Device security, too, is paramount to ensuring volunteers are not putting demonstrators (or themselves) at risk of further repression from state authorities. Peace Teams did not depend on just digital technologies to support or enable tactics, but rather fit those technologies within their tactical and organizational structures, maintaining a stable of digital, analog, and human-to-human tools.

Teams coordinate and share critical information to support de-escalation through point-to-point communication via encrypted message services. Peace Team members most commonly reported using the encrypted SMS service Signal, and to a lesser extent WhatsApp. Although these tools can support situational awareness, they are just one communication tool among several others, including hand signals and walkie-talkies.

For coordination and supporting spatial management tactics, Peace Team participants reported communicating to larger groups of people through broadcast tools such as microphones or megaphones. They also use broadcasting to communicate the norms and expectations for a demonstration.

Social media monitoring plays a role in situational awareness to support all tactics through the remote support teams. One remote support member described a TweetDeck display tailored to a particular demonstration, through which they gather information from trustworthy journalists, social movement organizations, and activists live-tweeting or live-streaming from the ground. Actionable information then follows the coordination channels via Signal, typically sent to on-the-ground team leaders who can respond accordingly.

Smartphones are multi-purpose, as in addition to providing access to the communication channels, they also support some useful apps like the American Civil Liberties Union (ACLU) app to record and report police misconduct. However, participants approached 
these devices with skepticism. Recounting stories of police seizing devices and breaking into them to harvest information on activists, members are cautious about smartphone use in demonstration. Through their alignment with demonstrators and social movement organizations, their networks of contacts commonly include individuals that state authorities are interested in. Furthermore, Peace Team members were also aware of how state authorities can track devices within a broad surveillance apparatus that renders smartphone use risky. So despite the potential for more advanced technological support through these devices (e.g. multiple participants discussed the possibility of maps in supporting geospatial awareness), concerns about device security under state surveillance apparatus limits these possibilities. How technologies could be used against activist allies of Peace Teams spurs mistrust of more advanced tools.

\section{Discussion}

We yield theoretical insights by a) casting de-escalatory tactics as a confluence of social and material intra-actions, and b) exploring bases of trust as mechanisms of the assemblage's configuration.

\subsection{De-escalatory Tactics as a Confluence of Social and Material Intra-actions}

The simple model of de-escalation is that it involves a pair of social actors, primarily a de-escalator, such as a member of the Peace Team, and a de-escalatee, such as a counter-protester or demonstrator. Although in the case of spatial management tactics where the effect is diffused across a few different actors, for instance a moral authority's presence producing a de-escalatory space, it can still be considered a paired interaction between an individual and a group.

However, a sociomaterial perspective of these tactics illuminates that de-escalatory tactics are not intra-actions composed of subject-object social dyads, but rather as a confluence of social and material intra-actions. While the tactics give the appearance of a local resolution to a localized violence potential [6], the tactics rest on underlying intra-actions between the social and material. Physical and verbal de-escalatory tactics emerge through the direct efforts of social agents with coordination through communication tools, such as messaging apps and walkie-talkies. At distance, remote support teams draw information from social media to coordinate teams' responses to the location of escalatory elements, highlighting social media's material presence [8]. In some cases, the literal materiality of a tool formed the core of the tactic, such as using the smartphone as the centerpiece of a distracting conversation with an escalated person.

Spatial tactics by their nature engage the qualities of the material environment, depending on use of proximity and separation to create spaces with de-escalatory potential. Tactics that leverage proximity or the separation of space represent a configuration of the material environment for de-escalation. Although spatial tactics are organized among social actors, the material environment are intra-active agents in de-escalation. Space and presence as known in peacekeeping [12] can therefore be considered a confluence of social and material intra-action, the latter being at the very least environmentally-based.

In such assemblages, boundaries between components are fluid, determined within phenomena [6]. Interestingly, the fluidity, or at least permeability, of these bounds in the protest-repression nexus can be observed through the eyes of the Peace Team: de-escalatory tools and tactics do not take place in a socio-material bubble. Rather, use of certain tactics or tools with certain entities could compromise the capacity to deploy de-escalatory tactics elsewhere, for example how interactions with police or cellphone recording could negatively impact relations with demonstrators.

This observation leads us to a theoretical insight starting with a question: what is the underlying mechanism that governs how lines of relationship between entities, along which de-escalatory tactics emerge, can be cut off due to the use of other tactics elsewhere in the assemblage? Under a sociomaterial perspective, this mechanism provides an explanation of the assemblage's dynamism that informs decision-making by Peace Teams. In the next section, we argue for bases of trust as this mechanism.

\subsection{Bases of Trust in the Assemblage}

Notions of trust permeated respondents' discussions, causing us to reflect on how this substantial phenomenon affects the shape and form of the sociomaterial assemblage. On the one hand, interactions with police can only go so far as they do not communicate a misalignment of shared values with social movements. When there is a perception that values are no longer shared, organizations can halt the relationship with Peace Teams altogether, or vice versa. On the other hand, relationships with tools are also depended on trust. A smartphone, for all its capacity to store and record information, expresses its power differently depending upon the embedding phenomenon. In the hands of a Peace Team member, it is a force of de-escalation, 
coordination, and peace. When seized by the state, it is a force of surveillance and oppressive control.

Viewing this space as a sociomaterial assemblage, distinctions between the social and material is fluid and determined within phenomena. What we consider intentions, values, and expectations have parallel expressions across both social and material actors. This parallel, we argue, stems from the local enactment of trust within these phenomena. In particular, it is an enactment of the bases of trust. Earle and Siegrist's [43] conception of trust builds from a basis in morally relevant information. It is through an assessment of similar intentions, values, and expectations about the future $[43,44]$ that trust is based. Socially, the decision to engage with police enacts a particular set of values, expectations and intentions. Trust breaks down when demonstrators view these bases as misaligned with their own. Peace Teams predict this, and choose to limit interactions with state authorities (or at least navigate them carefully). Materially, advanced tools are viewed with only limited trust as they can become tools of oppression when co-opted by entities misaligned with the Peace Teams' values. There is therefore a parallel caution between social and material entities that is the result of a predicted possible expression of misaligned values.

PytlikZillig and Kimbrough's [45] analysis of trust literature showed that multiple scholars speak to the vulnerability of the trustor [46] and a positive expectation of the trustee [47] that together make trust meaningful. Police mistreatment of activists discourages vulnerability, and Peace Teams can in turn become sources of added vulnerability for social movements, for instance in engaging with police. Technologies too can become sources of vulnerability in a similar fashion as they hold substantial information not just about Peace Teams, but activists as well. And so when positive expectations are violated (e.g. police misconduct or Peace Teams passing information to police), lines of trust (be they social or material) become sources of vulnerability.

Thus, entities enact different values in different phenomena, and perceived misalignment leads to mistrust. Furthermore, trust in social and material actors hinges upon their potential as sources of vulnerability through their connection or exploitation by other mistrusted entities in the assemblage. Enactment is not in isolation from other enactments, and perceived values misalignment combined with possibly exploitation of vulnerable entities breaks down lines of relationship between social and material actors, and in turn, the potential for de-escalatory intra-actions. Participant emphasis on trust stems from its critical role in producing this dynamism in the sociomaterial assemblage.

\subsection{Contributions to Scholarship and Practice}

Scholarship shows that maintaining nonviolent discipline supports the overall efficacy of social movements [3] and thus supports progress in liberal democracies. Peace Teams as de-escalatory forces are therefore potent in a healthy, evolving democracy. This study continues Julian's tactical dimensions of Peace Teams $[16,14]$ by adding empirical depth and dimensions of tactics, depicting its manifestation in contemporary demonstration and the entanglement of dimensions in practice.

Furthermore, viewing Peace Team work through the sociomaterial lens garnered theoretical insights for sociomaterial scholars. First, we argued that de-escalatory tactics as intra-action constitute a confluence of intra-activity, whereby tactics emerge from social and material entities in relation to one another. This provides empirical grounding to Barad's [6] sociomaterial scholarship within a novel domain. We then import scholarship on trust [43, 44, 45, 47, 46], and extending trust research in peace to sociomateriality in demonstration [11], arguing from a sociomaterial perspective its role in shaping the configuration of the sociomaterial assemblage in parallel ways between social and material actors.

For Peace Teams, there is benefit to regarding their relationship with social and material entities in parallel ways, particularly with regards to trust. Intra-actions with the social (e.g. police) and material (e.g. smartphones) display parallel trust implications based on the observation that no intra-action takes place in a bubble. At the same time, tactics as a confluence of intra-actions suggests that maximizing trusting relations with the social and material maximizes de-escalatory capacity. However, these connections are often in tension. First, communicating with certain entities like police in de-escalation can have a negative impact on trust with social movements. Second, advanced technologies can have greater potential to support de-escalation, but also introduce higher risk to social movements and Peace Teams themselves. While social movement research focuses largely on digital technologies like social media [8], there is space for lower technology solutions like walkie-talkies. Therefore, a critical component of de-escalatory work is the inherent risk management that must be involved in decision-making processes around tactics and tools, and remaining flexible thinkers with regards to tool selection. 


\section{Limitations and Future Directions}

This analysis could benefit from additional contribution from more Peace Teams and more overall participants (although the sample's expert perspectives mitigated the smaller numbers). Additionally, triangulation from additional data sets like observation of protests or team practices would also be beneficial, but is outside the scope of this particular study. We intend for future research to connect more participants and new data sets with these findings.

Further, while we focused on tactics and tools, there is value to exploring and problematizing non-violent interventions with a lens on power dynamics and positions of privilege. Trust also emerged from our findings as a critical mechanism, and further research should explore with more theoretical depth its impact on the socio-material assemblage. Due to size constraints, we could not explore these topics adequately, but will seek to extend to do so as the research progresses.

\section{Conclusion}

With nonviolent discipline a critical aspect of effective social movements and in turn a healthy democracy [3], Peace Teams can maximize social movement efficacy through their de-escalatory tactics. In this article, we set out to analyze Peace Teams through a sociomaterial lens, casting these tactics as intra-action within the protest-repression nexus, itself a sociomaterial assemblage. Through semi-structured interviews and focus groups, we dimensionalized current Peace Team tactics across the communicative, physical, and spatial. In identifying the variety of tools that underlie these tactics from coordination, situational awareness, and even direct materiality (e.g. cellphones as distracting and features of the material environment), we identified de-escalatory tactics as a confluence of intra-action between social and material actors. This lead us to a theoretical insight about the bases of trust as an underlying mechanism for understanding the dynamic nature of intra-actions in the protest-repression assemblage. While bases of trust underlie social connections, they also influence material ones, as tools like IT artifacts can be co-opted by mistrusted groups and in turn compromise trusted connections to other social entities, thus shaping the assemblage. Our work extends scholarship on the sociomateriality of protest to Peace Teams as a distinctive organization active with (but distinct from) social movement organizations [36, 8], bridging to trust scholarship [43, 44, 11], and extending understanding of unarmed civilian peacekeeping tactics [16, 14].
For practitioners, this view highlights the need to remain flexible thinkers with regards to tools and their materiality given the interconnectedness of actors within the protest-repression nexus.

\section{References}

[1] J. Umamaheswar, "Policing and Racial (In)Justice in the Media: Newspaper Portrayals of the "Black Lives Matter" Movement," Civil Sociology, vol. March, pp. 1-13, 2020.

[2] O. Price and J. Baker, "Key components of de-escalation techniques: A thematic synthesis," International journal of mental health nursing, vol. 21, no. 4, pp. 310-319, 2012.

[3] M. J. Stephan and E. Chenoweth, Why Civil Resistance Works: The Strategic Logic of Nonviolent Conflict. Columbia University Press, 2012.

[4] S. Drucker and G. Gumpert, "he Unsquared Square or Protest and Contemporary Publics," First Amendment Studies, vol. 49, no. 2, pp. 138-149, 2015.

[5] A. De Souza E Silva, "From cyber to hybrid: Mobile technologies as interfaces of hybrid spaces," Space and Culture, vol. 9, no. 3, pp. 261-278, 2006.

[6] K. Barad, "Posthumanist Performativity: Toward an Understanding of How Matter Comes to Matter," in A Feminist Companion to the Posthumanities (C. Asberg and R. Braidotti, eds.), ch. 19, pp. 223-240, Springer International Publishing, 2018.

[7] K. Kautz and T. B. Jensen, "Sociomateriality at the royal court of IS: A jester's monologue.," Information and Organization, vol. 23, no. 1, pp. 15-27, 2013.

[8] M. Tarafdar and D. Kajal Ray, "Role of Social Media in Social Protest Cycles: A Sociomaterial Examination," Information Systems Research, vol. 7047, no. Koopmans 2007, pp. 1-25, 2021.

[9] P. Gelderloos, The failure of nonviolence. Left Bank Books Seattle, 2015.

[10] T. Hastings, "Why Riot? Toward a Typology of Social Unrest," LA Progressive, may 2021.

[11] J. M. Whitehill, D. W. Webster, S. Frattaroli, and E. M. Parker, "Interrupting violence: How the CeaseFire program prevents imminent gun violence through conflict mediation," Journal of Urban Health, vol. 91, no. 1, pp. 84-95, 2014.

[12] R. Julian and C. Schweitzer, "The Origins and Development of Unarmed Civilian Peacekeeping," Peace Review, vol. 27, no. 1, pp. 1-8, 2015.

[13] O. Plesz, "Unarmed Civilian Peacekeeping As An Appropriate Institutionalised Answer to Conflict-Related Sexual Violence," The Responsibility to Protect Student Journal, vol. 2, no. 2, pp. 33-47, 2018.

[14] R. C. Julian, "Unarmed Civilian Peacekeeping," Peacekeeping Challenges and the Responsibility to Protect (R2P), p. 2016, 2016.

[15] S. James, “The Interrupters," 2012.

[16] R. Julian, "The transformative impact of unarmed civilian peacekeeping," Global Society, vol. 34, no. 1, pp. 99-111, 2020. 
[17] R. Julian and R. Gasser, "Soldiers, Civilians and Peacekeeping-Evidence and False Assumptions," International Peacekeeping, vol. 26, no. 1, pp. 22-54, 2019.

[18] M. Cerda, M. Tracy, and K. M. Keyes, "Reducing urban violence: a contrast of public health and criminal justice approaches," Epidemiology, vol. 29, no. 1, pp. 142-150, 2018.

[19] N. Ritter, "CeaseFire: A Public Health Approach to Reduce Shootings and Killings," National Institute of Justice Journal, no. 264, pp. 20-25, 2009.

[20] D. W. Webster, J. M. Whitehill, J. S. Vernick, and E. M. Parker, "Evaluation of Baltimore's Safe Streets Program: Effects on Attitudes, Participants' Experiences, and Gun Violence," tech. rep., Johns Hopkins Center for the Prevention of Youth Violence, Baltimore, MD, 2012.

[21] I. Bramsen, "Avoiding violence: Eleven ways activists can confine violence in civil resistance campaigns," Conflict Resolution Quarterly, vol. 36, no. 4, pp. 329-344, 2019.

[22] C. Schweitzer, "Civilian Peacekeeping: A Barely Tapped Resource," in Civilian Peacekeeping: A Barely Tapped Resource (C. Schweitzer, ed.), ch. 1, pp. 1-76, Sozio-Publishing, 2010.

[23] E. Chenoweth, E. Perkoski, and S. Kang, "State Repression and Nonviolent Resistance," Journal of Conflict Resolution, vol. 61, no. 9, pp. 1950-1969, 2017.

[24] S. Carey, "The Dynamic Relationship between Protest and Repression," Political Research Quarterly, vol. 59, no. 1, pp. 1-11, 2006.

[25] P. D. Almeida, Waves of protest: popular struggle in El Salvador, 1925-2005, vol. 29. University of Minnesota Press, 2008.

[26] A. Honari, "Responses to Repression," Sociopedia, pp. 1-15, 2017.

[27] S. R. Bell and A. Murdie, "The apparatus for violence: Repression, violent protest, and civil war in a cross-national framework," Conflict Management and Peace Science, vol. 35, no. 4, pp. 336-354, 2018.

[28] E. H. Ritter and C. R. Conrad, "Preventing and responding to dissent: The observational challenges of explaining strategic repression," American Political Science Review, vol. 110, no. 1, pp. 85-99, 2016.

[29] S. Carey, "The use of repression as a response to domestic dissent," Political Studies, vol. 58, no. 1, pp. 167-186, 2010.

[30] A. Otero, J. L. Carballido, L. Salgado, J. I. Canudo, C. Garrido, I. Kecerdasan, and P. Ikep, "How Do "Violent Flanks" Affect the Outcomes of Nonviolent Campaigns?," Peace Science Digest, apr 2016.

[31] L. Wood, "Policing counter-protest," Sociology Compass, vol. 14, no. 11, pp. 1-10, 2020.

[32] B. Bliesemann de Guevara, E. Furnari, and R. Julian, "Researching with 'Local' Associates: Power, Trust and Data in an Interpretive Project on Communities' Conflict Knowledge in Myanmar," Civil Wars, vol. 22, no. 4, pp. 427-452, 2020.

[33] R. Julian, B. Bliesemann de Guevara, and R. Redhead, "From expert to experiential knowledge: exploring the inclusion of local experiences in understanding violence in conflict," Peacebuilding, vol. 7, no. 2, pp. 210-225, 2019.
[34] A. Young, L. Selander, and E. Vaast, "Digital organizing for social impact: Current insights and future research avenues on collective action, social movements, and digital technologies," Information and Organization, vol. 29 , no. 3 , p. $100257,2019$.

[35] L. Selander and S. L. Jarvenpaa, "Digital action repertoires and transforming a social movement organization," MIS Quarterly: Management Information Systems, vol. 40, no. 2, pp. 331-352, 2016.

[36] K. Barad, "Posthumanist performativity: Toward an understanding of how matter comes to matter," Signs: Journal of women in culture and society, vol. 28, no. 3, pp. 801-831, 2003.

[37] W. J. Orlikowski, "Sociomaterial practices: Exploring technology at work," Organization Studies, vol. 28, no. 9, pp. 1435-1448, 2007.

[38] G. Deleuze and F. Guattari, A Thousand Plateaus: Capitalism and Schizophrenia. Minneapolis; London: University of Minnesota Press, 1987.

[39] W. J. Orlikowski and S. V. Scott, "10 Sociomateriality: Challenging the Separation of Technology, Work and Organization," The Academy of Management Annals, vol. 2, no. 1, pp. 433-474, 2008.

[40] V. Braun and V. Clarke, "Using thematic analysis in psychology," Qualitative Research in Psychology, vol. 3, no. 2, pp. 77-101, 2006.

[41] V. Braun, V. Clarke, N. Hayfield, and G. Terry, "Thematic Analysis," in Handbook of Research Methods in Health Social Sciences (P. Liamputtong, ed.), pp. 1-18, 2018.

[42] Boundless Love Project, "The CLARA Method of De-Escalation," 2020.

[43] T. C. Earle and M. Siegrist, "Morality Information, Performance Information, and the Distinction Between Trust and Confidence," Journal of Applied Social Psychology, vol. 36, no. 2, pp. 383-416, 2006.

[44] T. C. Earle, M. Siegrist, and H. Gutscher, "Trust, Risk Perception and the TCC Model of Cooperation," in Trust in Cooperative Risk Management: Uncertainty and Scepticism in the Public Mind (T. C. Earle, M. Siegrist, and H. Gutscher, eds.), ch. 1, pp. 1-49, London: Earthscan Publications, 2007.

[45] L. M. PytlikZillig and C. D. Kimbrough, "Consensus on conceptualizations and definitions of trust: Are we there yet?," Interdisciplinary Perspectives on Trust: Towards Theoretical and Methodological Integration, pp. 17-47, 2016.

[46] G. Dietz and D. N. Den Hartog, "Measuring trust inside organisations," Personnel review, 2006.

[47] R. C. Mayer, J. H. Davis, and F. D. Schoorman, “An integrative model of organizational trust," Academy of management review, vol. 20, no. 3, pp. 709-734, 1995. 